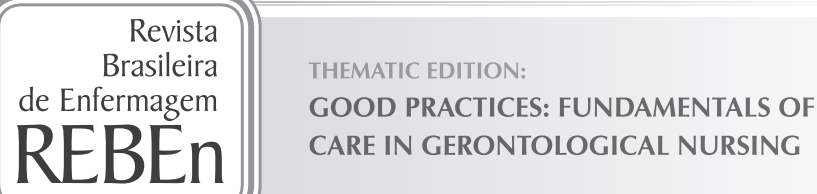

\title{
Falls in long-term care institutions for elderly people: protocol validation
}

\author{
Queda nas Instituições de Longa Permanência para Idosos: validação de protocolo \\ Caída en Residencias Geriátricas: validación de protocolo
}

\section{Cristina Rosa Soares Lavareda Baixinho', Maria dos Anjos Coelho Rodrigues Dixe", Maria Adriana Pereira Henriques ${ }^{\prime}$}
'Escola Superior de Enfermagem de Lisboa, Nursing Research \& Development Unit. Lisbon, Portugal. "Instituto Politécnico de Leiria, School of Health, Health Investigation Unit. Leiria, Portugal.

How to cite this paper:

Baixinho CRSL, Dixe MACR, Henriques MAP. Falls in long-term care institutions for elderly people: protocol validation. Rev Bras Enferm [Internet]. 2017; 70(4):740-6. [Thematic Edition "Good Practices: Fundamentals of care in Gerontological Nursing"] DOI: http://dx.doi.org/10.1590/0034-7167-2017-0109

Submission: 02-15-2017_Acceptance: 04-02-2017

\section{ABSTRACT}

Objectives: To validate the content of a fall management risk protocol in long-term institutions for elderly people. Methods: Methodological, quanti-qualitative study using the Delphi technique. The tool, based on the literature, was sent electronically to obtain consensus among the 14 experts that meet the defined inclusion criteria. Results: The 27 indicators of the protocol are organized in three dimensions: prepare for the institutionalization (IRA $=.88)$; manage the risk of falls throughout the institutionalization $($ IRA $=.9)$; and lead the communication and formation $(I R A=1)$, with a $C V I=.91$. Two rounds were performed to get a consensus superior to $80 \%$ in every item. Conclusion: The values obtained in the reliability test $(>0.8)$ show that the protocol can be used to meet the intended goal. The next step is the clinic validation of the protocol with residents of long-term care institutions for elderly people. Descriptors: Accidental Falls; Aged; Accident Prevention; Nursing; Institutionalization.

\section{RESUMO}

Objetivos: Validar o conteúdo de um protocolo para a gestão do risco de queda em Instituições de Longa Permanência para Idosos. Método: Estudo metodológico, de abordagem quantiqualitativa, utilizando a técnica de Delphi. O instrumento, construído com base na literatura, foi enviado por via electrónica, para obter consenso entre os 14 peritos que respeitam os critérios de inclusão definidos. Resultados: Os 27 indicadores do protocolo estão organizados em três dimensões: Preparar a Institucionalização (IRA=,88); Gerir o Risco de Queda ao longo da Institucionalização (IRA=,9) e Liderar a comunicação e formação (IRA=1), com um CVI=,91. Foram efetuadas duas rodadas para se obter consenso superior a $80 \%$ em todos os itens. Conclusão: Os valores obtidos no teste de fidedignidade $(>0,8)$ atestam que o protocolo pode ser utilizado para atingir o fim que se pretende. A próxima etapa é a validação clínica do protocolo com idosos residentes em Instituições de Longa Permanência para Idosos.

Descritores: Acidentes por Quedas; Idosos; Prevenção de Acidentes; Enfermagem; Institucionalização.

\section{RESUMEN}

Objetivos: Validar el contenido de un protocolo para gestión de riesgo de caídas en Residencias Geriátricas. Método: Estudio metodológico, de abordaje cualicuantitativo, utilizando técnica de Delphi. El instrumento elaborado con base en la literatura fue enviado por vía electrónica para obtener consenso entre los 14 peritos que observan los criterios de inclusión definidos. Resultados: Los 27 indicadores del protocolo están organizados en tres dimensiones: Preparar la Institucionalización (IRA =,88); Gerenciar el Riesgo de Caída durante la institucionalización (IRA=,9); y Liderar la comunicación y formación (IRA=1), con un $\mathrm{CVI}=$,91. Fueron efectuadas dos rondas para obtener consenso superior al $80 \%$ en todos los ítems. Conclusión: Los valores obtenidos en el test de fidelidad $(>0,8)$ certifican que el protocolo puede utilizarse para alcanzar el fin pretendido. La siguiente etapa será la validación clínica del protocolo con ancianos que moren en Residencias Geriátricas.

Descriptores: Accidentes por Caídas; Ancianos; Prevención de Accidentes; Enfermería; Institucionalización.

$$
\text { CORRESPONDING AUTHORＣristina Lavareda BaixinhoＥmail: crbaixinho@esel.pt }
$$




\section{INTRODUCTION}

Falls are a recurrent problem for older people and a matter of concern in long-term care (LTC) institutions for the elder$\mid y^{(1-3)}$, where their incidence varies between $34 \%$ and $67 \%$. They are a common cause of institutionalization and affect the independent residents of LTC facilities ${ }^{(5)}$.

The incidence of fall-related injuries is higher in institutionalized elderly ${ }^{(6)}$ than in older people that live at home, which makes this type of accident an important cause of morbidity and mortality in institutionalized elderly ${ }^{(3)}$. It is estimated that falls originate from 6,000 to 9,000 hospital admissions in this population every year, with an average length of stay of 12 to 20 days ${ }^{(7)}$.

Controlling this problem is difficult because the risk of fall is complex and multifactorial. However, in a rapidly aging population, the need emerged for the transfer of knowledge as a proactive and systematic measure to prevent falls. This effort must integrate policies, prevention, and practice ${ }^{(8)}$, with a multiprofessional approach. The authors emphasize that prevention may have several formats, but must involve different professionals ${ }^{(7)}$.

Both in the level of healthcare policy definition and in direct care of the elderly, nurses are the most qualified and suitable professionals to identify and categorize risk and to plan, implement, and evaluate prevention programs ${ }^{(4)}$, playing a key role in the assurance of quality of care in LTC units ${ }^{(4)}$.

In the interface between the appointment and the analysis of research results for this public healthcare issue, the need arises to outline and validate an intervention protocol for fall management risk in LTC institutions that allows nurses to use tools and interventions in clinical practice based on investigation, and assess the results of nursing care. Research has been useful to identify single and multiple sets of interventions that effectively decrease the prevalence of falls and associated injuries, but there is no intervention protocol for nursing clinical practice dedicated to LTC institutions that allows a systemic approach to maintain the safety of the elderly.

Therefore, the goal of the present study is to evaluate the content of a fall management risk protocol in LTC institutions.

\section{METHODS}

\section{Ethical aspects}

This study is part of an investigation into risk management of falls in equipment for the elderly and has the approval of the Ethics Committee of the Catholic University of Portugal.

Prior contact was necessary to obtain the authorization of the professionals to join the team, and the referral to the instrument by the participants assumes the will to participate in the research. For this reason, signature of the free and informed consent form was not required.

\section{Type of study}

Fall risk management in LTC facilities is a complex process that implies keeping the elderly safe throughout the entire period of institutionalization. To validate a fall risk management protocol for LTC units, a set of indicators was sent to a group of experts whose assignment was the evaluation of its pertinence and contribution to solve this serious public healthcare issue.

This methodological, quanti-qualitative study was conducted from February 2015 to July 2016 and the Delphi technique was used to obtain consensus among the experts regarding the propositions submitted to analysis. The methodological choice was state of the art and the goal of the study. This technique allowed access to geographically distant people, the production of a profusion of high quality and high specificity ideas, the possibility of individual thinking, and the integration and synergy of ideas among experts, without the drawbacks of face-to-face meetings ${ }^{(9)}$.

\section{Sample}

The intentional sample consisted of 14 experts that met the predefined inclusion criteria: to have more than five years of experience, with published research in the area of risk and/or prevention of falls in the elderly. The researchers opted for a heterogeneous sample, advocated by some authors to assure the validity of the results, given that multidisciplinarity provides a more valid predictive consensus ${ }^{(10)}$.

\section{Protocol}

The indicators submitted for evaluation by the examining board originated from a literature review and the results of research on this subject in LTC institutions. The analysis of interventions with emphasis on fall prevention, as well as good quality interventions that do not stress this aspect and the theoretical framework of Meleis's Theory of Transitions allowed categorization of the indicators, at first, into three aspects: prepare for the institutionalization; manage the risk of falls throughout the institutionalization; and lead the communication and formation.

A previous contact was established to explain the goal of the study and avoid the abstention of the participants.

The questionnaire was designed and sent through Google Drive $^{\circledast}$. The experts were asked to give their opinion about the indicators; scores of $-1,0$, and 1 point were given to a non-pertinent indicator ("I do not have an opinion") and a pertinent indicator, respectively.

A pretest to evaluate the readability of the items was carried out with five experts that did not belong to the definitive examining board $^{(9)}$.

Two rounds of evaluation ${ }^{(9-10)}$ were conducted to get a consensus higher than $80 \%$ in all of the answers. After the referral of the instrument in the first round, the propositions were analyzed with descriptive statistical tools and suggestions for alterations/rewriting of the items were considered. The level of consensus and the suggestions were integrated according to the chosen theoretical framework.

The participants gave feedback on the answers, and the indicators that obtained a consensus lower than $80 \%$ were reformulated between rounds, following the reformulation suggestions of the examining board. In the second round, the items that reached the previously stipulated $80 \%$ consensus $^{(9-10)}$ were excluded. New questions were not introduced in the questionnaire because the analysis of the answers to the open-ended questions in the first round did not point to any new queries. 


\section{Analysis of the results}

For validation of the protocol content, the Content Validity Index was applied to each item (CVII) and to the whole document (CVI). Also, the Interrater Agreement (IRA) was used to evaluate the reliability or the inter-rater reliability. To calculate the CVI for individual items and the entire protocol, the number of participants that gave a score of 3 or 4 in a Likert scale was divided by the number of participants that judged the item or the instrument ${ }^{(11)}$. IRA was obtained by dividing the number of items with a consensus higher than $80 \%$ among the experts by the total number of items in each dimension ${ }^{(11)}$.

SPSS version 21 software performed the statistical treatment of the data.
The suggestions given by the experts were analyzed within the theoretical framework and introduced in the second round.

\section{RESULTS}

The sample, consisting of 14 female experts, was heterogeneous regarding the professional formation of the members, although all of them had experience in researching and publishing about falls in the elderly. Regarding professional experience, there were eight nurses, one medical doctor, two physical educators, one psychologist, and two physical therapists. Eight were Portuguese and six were Brazilian.

Chart 1 shows the dimensions and their indicators, submitted for evaluation by the examining board.

Chart 1 - Expert agreement (first round of the evaluation) regarding the items of a fall risk management protocol, Lisbon, Portugal, 2016

\begin{tabular}{|c|c|c|c|c|}
\hline & Dimensions of the fall risk management protocol for LTC institutions* & CVII** I & IRA $* * *$ & $\mathrm{CVI} * * * *$ \\
\hline \multicolumn{4}{|c|}{ Preparing the institutionalization } & \multirow{30}{*}{0.91} \\
\hline 1 & Meets the elderly and their family before the admittance to a LTC unit*. & 0.86 & \multirow{9}{*}{0.77} & \\
\hline 2 & Applies an assessment scale for fall risk. & 0.93 & & \\
\hline 3 & Applies a scale to evaluate the elderly's practices and behaviors regarding the fall risk management. & 0.86 & & \\
\hline 4 & Describes rules of good practice. & 0.93 & & \\
\hline 5 & Tells the fall prevalence rate in the LTC institution*. & 0.71 & & \\
\hline 6 & Contracts the commitment of the family in the elderly person's safety. & 0.86 & & \\
\hline 7 & Informs the elderly person of the need to report every fall episode. & 0.93 & & \\
\hline 8 & Formalizes the care continuity with the family nurse. & 0.79 & & \\
\hline 9 & Hands written information about the criteria for clothes/shoes to bring to the institution. & 1.0 & & \\
\hline \multicolumn{4}{|c|}{ Managing the fall risk throughout the institutionalization } & \\
\hline 10 & Evaluates the individual fall risk with a risk assessment tool. & 1.0 & \multirow{10}{*}{0.9} & \\
\hline 11 & Controls the environment and equipment. & 1.0 & & \\
\hline 12 & Manages the daily activities of the elderly. & 0.93 & & \\
\hline 13 & Manages the care given by different professionals. & 0.93 & & \\
\hline 14 & Determines the task delegation mechanisms to other professionals. & 0.79 & & \\
\hline 15 & Evaluates the practices and behaviors of the professionals regarding fall risk management. & 1.0 & & \\
\hline 16 & Evaluates the practices and behaviors of the elderly regarding fall risk management. & 0.86 & & \\
\hline 17 & Selects safe supporting products for the execution of daily activities. & 0.86 & & \\
\hline 18 & Monitors the fall episodes. & 0.93 & & \\
\hline 19 & Implements strategies to control fall consequences and prevent the decrease of functionality in the post-fall period. & 1.0 & & \\
\hline \multicolumn{4}{|c|}{ Leading communication and formation } & \\
\hline 20 & Decides as a team the preventive measures to be implemented. & 1.0 & \multirow{8}{*}{1.0} & \\
\hline 21 & Tells the family the individual fall risk factors of the elderly person. & 1.0 & & \\
\hline 22 & Tells the family the implemented measures. & 0.86 & & \\
\hline 23 & Evaluates the impact of the implemented preventive measures. & 1.0 & & \\
\hline 24 & Communicates and reports the fall episodes. & 0.93 & & \\
\hline 25 & Runs epidemiological studies. & 0.93 & & \\
\hline 26 & Registers the fall episodes in a national platform. & 0.86 & & \\
\hline 27 & Sets up the multidisciplinary team. & 1.0 & & \\
\hline
\end{tabular}

Notes: * Long-term care; ${ }^{*}$ Content Validity Index, applied to the items of the protocol; ${ }^{* * *}$ Interrater Agreement, applied to the protocol dimensions; ${ }^{* * *}$ Content Validity Index of the protocol 
After the referral of the form to the experts and an analysis of the answers, it was noticed that items 5, 8, and 14 did not attain a consensus higher than $80 \%$. Also, the reformulation suggestions given by the examining board were considered, and the items changed and resent. Regarding item 5, an expert (E) expressed her concern about the communication of fall prevalence to the elderly person and how it would influence the fear of falls, especially in individuals that had already had an episode, and whether this information would impact the fear of a new fall episode or its occurrence in the first days of institutionalization. The expert (E7) therefore disagreed on its pertinence. Another participant, who stated not to have an opinion, argued that the low literacy of the elderly and their families could hinder their understanding of this information and create anxiety about the chosen LTC unit (E11).
As for item 8, an expert stated not to have an opinion and two considered that the item was not pertinent. A participant that considered this item pertinent suggested its reformulation because not all of the population have a family nurse (E14).

Analysis of item 14 revealed a suggestion to make it clear that the nurse has to determine the task delegation mechanisms to hands-on healthcare professionals, instead of those with higher professional autonomy and a superior academic degree (E3).

After the rewrite, the changed items looked like this: (5) tells the family the fall prevalence rate in the LTC institution; (8) assures the care continuity, asking the primary care nurse for information; and (14) determines the task delegation mechanisms to hands-on professionals. At the end of the second round, these items obtained a consensus of $93 \%$, 93\%, and $86 \%$, respectively. Chart 2 exhibits the results after the second round of evaluation by the examining board.

Chart 2 - Expert agreement (second round, final version) regarding the items of a fall risk management protocol, Lisbon, Portugal, 2016

\begin{tabular}{|c|c|c|c|c|}
\hline & Dimensions of the fall risk management protocol for LTC institutions* & CVII* & IRA** & CVI*** \\
\hline \multicolumn{4}{|c|}{ Preparing the institutionalization } & \multirow{30}{*}{0.93} \\
\hline 1 & Meets the elderly person and their family before the admittance to a LTC unit*. & 0.86 & \multirow{9}{*}{1} & \\
\hline 2 & Applies an assessment scale for fall risk. & 0.93 & & \\
\hline 3 & Applies a scale to evaluate the elderly person's practices and behaviors regarding the fall risk management. & 0.86 & & \\
\hline 4 & Describes rules of good practice. & 0.93 & & \\
\hline 5 & Tells the family the fall prevalence rate in the LTC institution*. & 0.93 & & \\
\hline 6 & Contracts the commitment of the family in the elderly person's safety. & 0.86 & & \\
\hline 7 & Informs the elderly person of the need to report every fall episode. & 0.93 & & \\
\hline 8 & Assures the care continuity, asking the primary care nurse for information. & 0.93 & & \\
\hline 9 & Provides written information about the criteria for clothes/shoes to bring to the institution. & 1 & & \\
\hline \multicolumn{4}{|c|}{ Managing the fall risk throughout the institutionalization } & \\
\hline 10 & Evaluates the individual fall risk with a risk assessment tool. & 1 & \multirow{10}{*}{1} & \\
\hline 11 & Controls the environment and equipment. & 1 & & \\
\hline 12 & Manages the daily activities of the elderly. & 0.93 & & \\
\hline 13 & Manages the care given by different professionals. & 0.93 & & \\
\hline 14 & Determines the task delegation mechanisms to hands-on professionals. & 0.86 & & \\
\hline 15 & Evaluates the practices and behaviors of the professionals regarding fall risk management. & 1 & & \\
\hline 16 & Evaluates the practices and behaviors of the elderly person regarding fall risk management. & 0.86 & & \\
\hline 17 & Selects safe supporting products for the execution of daily activities. & 0.86 & & \\
\hline 18 & Monitors the fall episodes. & 0.93 & & \\
\hline 19 & Implements strategies to control fall consequences and prevent the decrease of functionality in the post-fall period. & 1 & & \\
\hline \multicolumn{4}{|c|}{ Leading communication and formation } & \\
\hline 20 & Decides as a team the preventive measures to be implemented. & 1 & \multirow{8}{*}{1} & \\
\hline 21 & Tells the family the individual fall risk factors of the elderly. & 1 & & \\
\hline 22 & Tells the family the implemented measures. & 0.86 & & \\
\hline 23 & Evaluates the impact of the implemented preventive measures. & 1 & & \\
\hline 24 & Communicates and reports the fall episodes. & 0.93 & & \\
\hline 25 & Runs epidemiological studies. & 0.93 & & \\
\hline 26 & Registers the fall episodes in a national platform. & 0.86 & & \\
\hline 27 & Sets up the multidisciplinary team. & 1 & & \\
\hline
\end{tabular}

Notes: *Long-term care; ${ }^{* *}$ Content Validity Index, applied to the items of the protocol; $* * *$ Interrater Agreement, applied to the protocol dimensions; $* * * *$ Content Validity Index of the protocol 


\section{DISCUSSION}

One of the greatest, if not the greatest, challenge in nursing as a science and a profession is the integration of research results and practice, aiming the development of the subject and a more efficient professional intervention. This contributes to the improvement of health care to the population and decreases the costs related to disease treatment/incapacity, rehabilitation, and complications associated with the processes of health/disease, promoting different transitions ${ }^{(12)}$.

Falls in the elderly are a typical example of the need to introduce research findings into nursing clinical practice. The aim of the protocol presented to the examining board in this study is to facilitate the introduction of research evidence in nursing clinical practice and decision making, as well as to provide conditions for a healthy transition in institutionalized elderly persons that experience different types of transition, often simultaneously ${ }^{(12)}$.

A literature survey allowed the organization of the protocol into three dimensions: prepare for the institutionalization; manage the fall risk throughout the institutionalization; and lead communication and formation. Twenty-four of 27 indicators obtained a consensus higher than $80 \%$ in the first round of evaluation.

In the second round, the number of participants changed $(n=10)$. This decrease of $29 \%$ in the number of experts corroborates the literature, which says that during a Delphi study the expected abstention rate is between $20 \%$ and $30 \%$ in the second round ${ }^{(10)}$. The smaller examining board did not affect the validity or the quality of the research results, once the experts had a deep knowledge of the subject and literature considers paramount the qualification of the judges, with no need of statistical representation in terms of number of participants in the study ${ }^{(9)}$.

Preparation for institutionalization is little discussed in the literature. However, it is known that one in five elderly people just admitted to LTC units fall within the first days of institutionalization $^{(13)}$. The incidence is higher than in residents who have been there longer, because the newcomer has to deal with an unknown environment ${ }^{(12-13)}$. Also, the physical space and the presence of the institution staff make the place different from home ${ }^{(5)}$, which hampers risk identification and control $^{(13)}$. Furthermore, the unknown environment decreases the elderly person's confidence in the execution of activities of daily living ${ }^{(14)}$. The institutionalized population is less independent and more often affected by chronic diseases in comparison with people living in the community ${ }^{(5)}$.

The transition to a institution is a moment of instability, and the intention of the nurse in this process is to interact with the patient toward an action to promote, reestablish, or facilitate health ${ }^{(12)}$.

Experts consider it pertinent that the preparation for institutionalization begins with a meeting with the elderly person and/or family before the admittance to the LTC facility, during which a fall risk assessment scale is applied, including the question "Did you fall in the last 12 months?" to anticipate the need for self-care supporting products or walking aids that allow the elderly person to keep safe. Experts also value the periodic identification of the elderly person's practices and behaviors in the fall risk management. Studies on the control of behavioral risk factors are few in comparison with the ones that address biophysiological risk factors. A paper recommends the use of the "Scale of Practices and Behaviors of Institutionalized Elderly to Prevent Falls" to evaluate the elderly person's practices and behaviors regarding communication of risk factors, safety in self-care, and accessibility of physical space $^{(15)}$. This preparation must include information about the institution's "good practice rules" for fall prevention and the contractualization of the family's commitment to the elderly person's safety, specifically in the choice of the clothes and shoes that they bring to the facility and that must be safe. Also, many institutionalized elderly persons leave the LTC facility to visit their families ${ }^{(16)}$, in whose houses falls may occur. As it is a risk factor, it must be communicated to the LTC staff.

As for item 8, one expert reported not to have an opinion and two considered the inclusion of the nonpertinent item. It must be stressed that these three experts do not practice healthcare activities, and this may have impacted their evaluation of the item's pertinence. Information transfer between different care levels is vital. Given the lack of studies in LTC facilities that address this aspect, some hospital investigations advocate that it is crucial to pay attention to the right information at hospital discharge to avoid recurrent falls and readmissions caused by them ${ }^{(17)}$. This is because the elderly, even high-risk ones, have little knowledge about the fall prevention approaches to implement after hospital discharge ${ }^{(18)}$.

In the dimension "manage the fall risk throughout the institutionalization," the indicators are complex because the fall risk management in LTC facilities is multifactorial ${ }^{(19)}$ and implies the management of the elderly person's activities of daily living in time, space, and action, as well as the management of the care given by other professionals.

As for time, because it has to be kept throughout the entire process of institutionalization, taking into account that time itself, along with aging, the inherent progressive decline of functionality and the increased probability of becoming sick and/or dependent, has a direct impact on self-care, and the professionals must guarantee the elderly person's safety and welfare $^{(19)}$. The former demands task delegation to other professionals that allows for the detection of poor practices and dealing with situations in which safety may be compromised ${ }^{(19)}$.

The spatial aspect is important because it is necessary to control extrinsic factors in fall risk, from the environment to equipment, as well as several supporting products and their maintenance, as regards using conditions, which includes processes that start with acquisition and end up in use, going through their maintenance and verification. An example is the incorrect use of walking aids associated with falls ${ }^{(6)}$, caused by their inadequacy to the type of gait of the elderly or by damage to the instruments. Tripping over the walking aids of other residents is often described as a cause of falls during walking ${ }^{(1)}$.

Regarding action, the practices and behaviors of the elderly $^{(15)}$ as well as the professionals must be monitored, improved, and evaluated.

After a fall episode, the elderly person may develop a fear of falling again, even if no injury has occurred in the first event ${ }^{(20)}$. This can lead to limitations in their activities, which causes a decrease in mobility and physical aptitude, consequently adding to 
the fall risk. This is why experts recommend monitoring fall episodes and implementing strategies that control fall consequences and prevent functionality decline in the post-fall period ${ }^{(16)}$.

The dimension "leading communication and formation" is the one that better scores at IRA. Evidence-based fall prevention is innovative and, by definition, represents new ways of working that require new knowledge, capacities, and skills that have to be learned and implemented in the profession ${ }^{(21)}$, so that the nurses can lead the processes in their teamwork.

In the first round, all of the experts considered that the preventive measures to be implemented must be decided by the team of professionals. The literature advocates that communication and teamwork are crucial for fall prevention, from risk assessment to adoption of preventive action and communication of fall episodes. These must be reported monthly to the team, which plays a key role in the implementation of better practices ${ }^{(21)}$.

Communication is a central element in a fall prevention program. Conversation between residents and professionals about preventive measures and health promotion may assure that specific and appropriate interventions are developed to decrease fall incidence ${ }^{(19)}$. Experts value communication with the family, as well as the reporting of fall episodes to the whole team. This information report by the elderly is important because recurrent falls happen at the patient's height ${ }^{(22)}$ and the description of the event allow the implementation of preventive measures based on the environment characteristics ${ }^{(22)}$.

The existence of educational programs about evidence-based fall prevention is essential for healthcare professionals working in LTC institutions ${ }^{(8)}$. Fall specialists attributions include assuring that the best practices are applied and selecting coaches with skills to improve the professionals' performance ${ }^{(21)}$. It is important for the leader of any fall prevention program and they must be included in the multidisciplinary team.

It is important to add that fall prevention programs in LTC institutions, in addition to comprising the structure, the process, and the result, have to be sensitive to the nature and properties of the different transitions ${ }^{(10)}$ that the residents may experience, not just to individualize the management, but also to promote an efficient comparison of results.

Finally, it is necessary to stress the importance of recording the fall episodes in a national platform, which would favor the continuity between different levels of care (P2).

\section{Study limitations}

Sending the instrument by electronic means increased the probability of bias in the experts' answers, not just because of misinterpretation, but also due to the possibility that the answers were influenced by other sources. The choice of a heterogeneous sample may hinder the evaluation of the indicators within the nursing reference framework.

\section{Contributions to nursing, health, or public policy areas}

Rigor in the application of the methodology and the high level of consensus among the experts show that the results are reliable and that the proposed protocol can be implemented by nurses in LTC facilities to decrease the prevalence of falls, guaranteeing that the fall risk is assessed even before the admission of the elderly. In this way, potential complication and individualized preventive measures can be anticipated. Staff leadership, in terms of communication and formation, is a crucial measure to assure the safety of the institutionalized elderly.

\section{CONCLUSION}

Security of the elderly and especially fall prevention are a social, economic and political issue that must be a matter of concern for the society, considering the individual consequences, the healthcare costs and the impact of falls in the elderly's functionality.

It is believed that the nurse must be the manager of fall prevention programs in LTC institutions. The existing literature associates fall prevention with singular and multifactorial interventions, but there are no validated protocols for the clinical practice of nurses working in LTC units.

This study allowed to validate the content of a fall risk management protocol in LTC institutions presenting three dimensions: prepare for the institutionalization; manage the risk of falls throughout the institutionalization; and lead the communication and formation. Based on the results of the research, the protocol validated by 14 experts defines 27 indicators that must guide the care to the elderly residing in LTC facilities to prevent fall episodes and their recurrence. The values obtained in the reliability test $(>0.8)$ reveal that the protocol can be used to achieve the intended goal. The next step in the investigation is clinical validation of the protocol with elderly residents of LTC facilities.

\section{ACKNOWLEDGEMENTS}

The authors want to thank the experts that evaluated the instrument for their availability, contributions, and high-quality work.

\section{REFERENCES}

1. Nitz J, Cyarto E, Andrews S, Fearn M, Fu S, Haines T, et al. Outcomes from the implementation of a facility-specific evidence-based falls prevention intervention program in residential aged care. Geriatr Nurs [Internet]. 2012 [cited 2016 Apr 27];33(1):41-50. Available from: http://dx.doi.org/10.1016/j.gerinurse.2011.11.002

2. Bösner S, Keller H, Wöhner C, Sönnichsen A, Baum E, Donner-Banzhoff N. Prevention of falls by outdoor-walking in elderly persons at risk ("power"): a pilot study. EUGMS [Internet]. 2012 [cited 2016 Apr 27];3:28-32. Available from: http://dx.doi. org/10.1016/j.eurger.2011.06.008 
3. Burland B, Martens P, Brownell M, Doupe M, Fuchs D. The Evaluation of a Fall Management Program in a Nursing Home Population. Gerontol [Internet]. 2013 [cited 2016 Apr 27];53(5):828-38. Available from: https://doi.org/10.1093/geront/gns197

4. Teresi JA, Ramirez M, Remler D, Ellis J, Boratgis G, Silver S, et al. Comparative effectiveness of implementing evidenced-based education and best pratices in nursing homes: effects on falls, quality-of-life and societal costs. Int J Nurs Stud [Internet]. 2013 [cited 2016 Nov 10];50(4):448-63. Available from: http://dx.doi.org/10.1016/j.ijnurstu.2011.07.003

5. Deandrea S, Bravi F, Turati F, Lucenteforte E, Vecchia C, Negri E. Risk fators for falls in older people in nursing homes and hospitals: a systematic review and meta-analysis. Arch Gerontol Geriatr [Internet]. 2013 [cited 2016 Nov 10];56(3):407-15. Available from: http://dx.doi.org/10.1016/j.archger.2012.12.006.

6. Grávalos GJD, Vásquez CG, Pereira VA, Payo RA, Araujo SA, Hermida SR. Fatores asociados con la aparición de caídas en ancianos institucionalizados: un estudio de cohortes. Rev Esp Geriatr Gerontol [Internet]. 2009 [cited 2013 Apr 04];44(6):301-4. Available from: http://dx.doi.org/10.1016/j.regg.2009.06.013

7. Speechley M. Knowledge translation for falls prevention: The view from Canada. J Safety Res [Internet]. 2011 [cited 2016 Apr 27];42(6): 453-9. Available from: http://dx.doi.org/10.1016/j.jsr.2010.09.004

8. Kalula SZ, Scott V, Dowd A, Brodrick K. Falls and fall prevention programmes in developing countries: Environmental scan for the adaptation of the Canadian Falls prevention curriculum for developing countries. J Safety Res [Internet]. 2011 [cited 2016 Nov 10];42(6):461-72. Available from: http://dx.doi.org/10.1016/j.jsr.2010.12.003

9. Scarparo AF, Laus AM, Azevedo ALCS, Freitas MRI, Gabriel CS, Chaves LDP. Reflections on the use of delphi technique in research in nursing. Rev Rene [Internet]. 2012 [cited 2016 Apr 27];13(1):242-51. Available from: http://www.redalyc.org/ pdf/3240/324027980026.pdf

10. Wright JTC, Giovinazzo RA. Delphi uma ferramenta de apoio ao planejamento prospectivo. Cad Pesq Admin [Internet]. 2000 [cited 2016 Apr 27];1(12):54-65. Available from: http://regeusp.com.br/arquivos/C12-art05.pdf

11. Bellucci Júnior JA, Matsuda LM. Construction and validation of an instrument to assess the Reception with Risk Rating. Rev Bras Enferm [Internet]. 2012 [cited 2016 Nov 10];65(5):751-7. Available from: http://www.scielo.br/pdf/reben/v65n5/06.pdf

12. Meleis Al. Transitions Theory: Middle Range and Situation Specific Theories in Research and Practice. New York: Springer Publishing Company; 2010.

13. Leland NE, Gozalo P, Teno J, Mor V. Falls in Newly Admitted Nursing Home Residents: A National Study. JAGS [Internet]. 2012 [cited 2016 Nov 10];60(5):939-45. Available from: http://dx.doi.org/10.1111/j.1532-5415.2012.03931.x

14. Pountney D. Preventing and managing falls in residential care settings. NRC [Internet]. 2009 [cited 2016 Nov 10];11(8):410-4. Available from: http://www.magonlinelibrary.com/doi/pdf/10.12968/nrec.2009.11.8.43320

15. Baixinho $\mathrm{CL}$, Dixe MA. Construction and validation of the scale of practices and behaviors of institutionalized elderly to prevent falls. UJPH [Internet]. 2016 [cited 2016 Apr 27];4(3):139-43. Available from: http://dx.doi.org/10.13189/ujph.2016.040303

16. Baixinho $\mathrm{CL}$, Dixe MA. Falls in institutions for older adults: characterization of fall occurrences and associated risk factors. Rev Eletr Enferm [Internet]. 2015 [cited 2016 Apr 27];17(4). Available from: http://dx.doi.org/10.5216/ree.v17i4.31858

17. Milisen K, Coussement J, Arnout H, Vanlerberghe V, De Paepe L, Schoevaerdts D, et al. Feasibility of implementing a practice guideline for fall prevention on geriatric wards: a multicentre study. Int J Nurs Stud [Internet]. 2012 [cited 2016 Apr 27];50(4):495-507. Available from: http://dx.doi.org/10.1016/j.jinurstu.2012.09.020

18. Hill AM, Hoffmann T, McPhail S, Beer C, Hill KD, Oliver D, et al. Evaluation of the sustained effect of inpatient falls prevention education and predictors of falls after hospital discharge-follow-up to a randomized controlled trial. J Gerontol A Biol Sci Med Sci [Internet]. 2011 [cited 2016 Nov 10];66(9):1001-12. Available from: http://dx.doi.org/10.1093/gerona/glr085

19. Duffy A. The assessment and management of falls in residential care settings. Br J Nurs [Internet]. 2013 [cited 2016 Apr 27];22(5):259-63. Available from: http://dx.doi.org/10.12968/bjon.2013.22.5.259

20. Sousa LMM, Marques-Vieira CMA, Caldevilla MNGN, Henriques CMAD, Severino SSP, Caldeira SMA. Risk for falls among community-dwelling older people: systematic literature review. Rev Gaúcha Enferm [Internet]. 2016 [cited 2016 Apr 27];37(4):e55030. Available from: http://dx.doi.org/10.1590/1983-1447.2016.04.55030

21. Fixsen D, Scott V, Blasé K, Naoom S, Magar L. When evidence is not enough: the challenge of implementing fall prevention strategies. J Safety Res [Internet]. 2011 [cited 2013 Apr 04];42(6):419-22. Available from: http://dx.doi.org/10.1016/j.jsr.2011.10.002

22. Ferreira DC, Yoshitome Y. Prevalência e características das quedas de idosos institucionalizados. Reben. [Internet]. 2010 [cited 2016 Apr 27];63(6):991-7. Available from: http://www.scielo.br/pdf/reben/v63n6/19.pdf 